Article

\title{
Fine Exploration and Control of Subway Crossing Karst Area
}

\author{
Jing Wang $\mathbb{D}$, Liping Li *, Shaoshuai Shi * ${ }^{\mathbb{D}}$, Shangqu Sun, Xingzhi Ba and Yijie Zhang \\ School of Qilu Transportation, Shandong University, Jinan 250061, China \\ * Correspondence: liliping@sdu.edu.cn (L.L.); shishaoshuai@sdu.edu.cn (S.S.)
}

Received: 13 May 2019; Accepted: 22 June 2019; Published: 26 June 2019

check for updates

\section{Featured Application: Accurate exploration and safety control of karst caves in subway construction.}

\begin{abstract}
A large number of subway projects need to cross all kinds of disaster sources during the construction process. When a disaster source is unknown and uncertain, it is difficult for tunnel stability analysis to conform to the actual situation, which is likely to cause serious geological disasters. Firstly, the accurate location of the source of the disaster is realized via the geophysical method, and the orientation of the target is determined. Secondly, real imaging of the geological disaster source is realized using fine three-dimensional scanning equipment. Finally, the coupling law of the seepage field, displacement field, and stress field of the tunnel surrounding rock are analyzed. The stability of the tunnel is analyzed, and the reasonable karst treatment method is put forward.
\end{abstract}

Keywords: disaster source; geophysical method; orientation of the target; reasonable karst treatment method

\section{Introduction}

The distribution area of karst in China is 3.65 million square kilometers, accounting for more than one-third of the territory. Karst is most developed in the Southern provinces of Guizhou, Hunan, Jiangxi, Sichuan, Yunnan, and Hubei, and in the Northern provinces of Hebei, Shandong, and Liaoning. Additionally, many karst development areas are distributed in metro construction cities, such as Jinan Metro, which needs to pass through hard rock water-rich caves [1], Wuhan Metro, which needs to pass through "honeycomb caves", Changsha Metro, which needs to pass through complex underwater caves, and so on. In the soluble strata, limestone may contain limestone fragments and fissures locally (Figure 1). The existence of limestone fissures provides water storage conditions and transportation channels for groundwater [2]. Caves of different sizes, shapes, and buried depths are formed due to the dissolution and erosion of groundwater [3]. If these caves are not accurately identified, the following risks are likely to occur:

1. Shield machine pitch, jamming or water inrush (Figure 2);

2. Karst cave collapse above the tunnel leading to the surface collapse;

3. During the operation period, vehicle vibration causing surface collapse or karst cave collapse under the segment, which leads to risks in train operation;

4. The existence of karst water leading to the continuous development of karst caves, which threatens the long-term operation of the metro. 


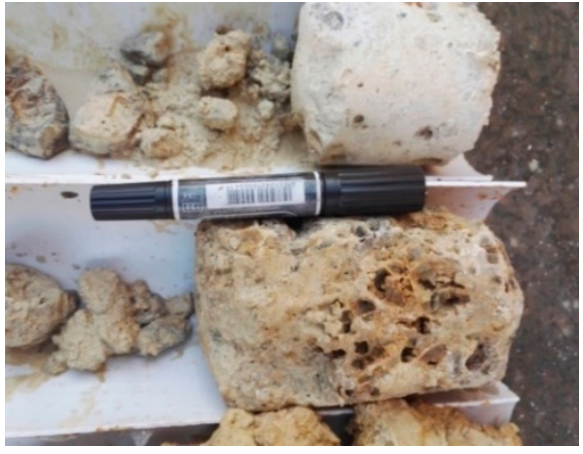

(a)

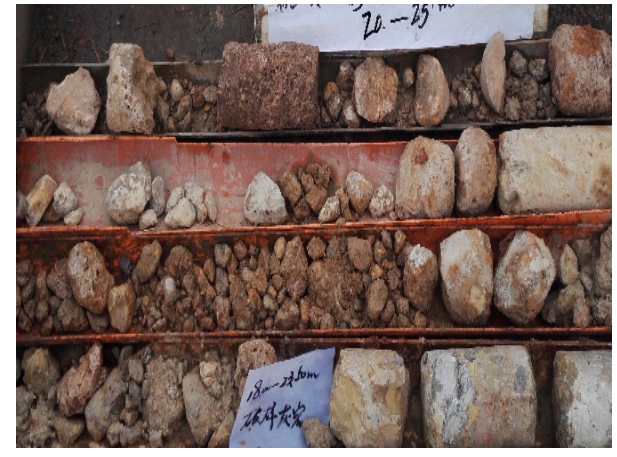

(b)

Figure 1. Dissolution limestone and limestone fragments. (a) dissolution limestone; (b) limestone fragments.

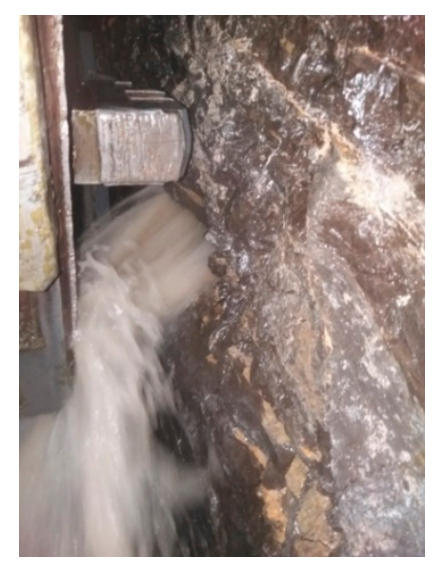

(a)

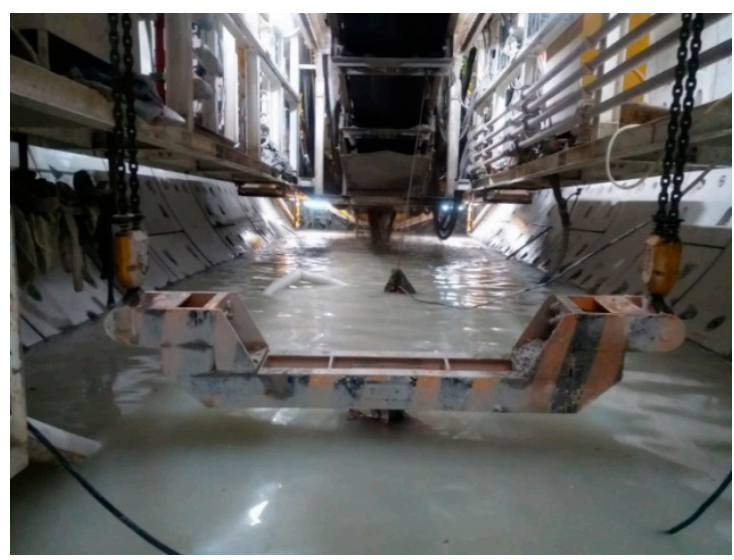

(b)

Figure 2. Water inrush from shield tunnel. (a) front of the tunnel; (b) inside the tunnel.

In the aspect of karst detection, a large number of geophysical methods (including electrical, electromagnetic, elastic wave, and microgravity) have emerged [4-13]. However, the geological conditions in the karst area are complex, and it is difficult to accurately investigate the underground conditions by a single geophysical method $[14,15]$. With the advancement of geophysical methods and interpretation techniques, great achievements have been made in karst exploration [16]. More successful detection cases demonstrate that comprehensive detection method can effectively reduce the uncertainty and reduce the error interpretation results when exploring the underground karst structure. However, geophysical prospecting methods can only locate karst caves, which is difficult to quantify. Borehole laser scanning technology is a method to get the point cloud data of the three-dimensional surface of the inner wall of the cavity by extending the probe with integrated laser scanning function into the cavity. Its principle is the same as that of the standing laser scanner, but its greatest advantage is the miniaturization of the laser probe, which can adapt to various narrow channels and space and get data deep into the rock mass $[17,18]$. At present, drilling laser technology is mainly used in the goaf of coal mine, but it is not combined with geophysical prospecting methods, which leads to the problem of blind drilling. Therefore, this paper synthetically determines the karst development area by means of various geophysical prospecting. Targeted drilling and quantitative exploration of karst cave by drilling laser are carried out. 


\section{Quantitative Exploration Method of Karst Cave Based on Three-Dimensional Laser Measurement}

\subsection{3-D Automatic Laser Scanning Technology}

Three-dimensional automatic laser scanning technology uses laser diodes to emit laser pulses. Laser pulses propagate to the target point under testing [19]. The photosensitive secondary tube receives laser signals reflected from the surface of the object. The "flight time" of the laser is calculated. The distance $\mathrm{L}$ between the scanner and the target point under testing is calculated by the speed of light $C$ and the "flight time" $\Delta t$. A precision clock control encoder synchronously measures transverse scanning angle observation value alpha and longitudinal scanning angle observation value beta of each laser pulse. Laser scanning three-dimensional measurement uses the internal coordinate system of the instrument. The $\mathrm{X}$-axis is in the transverse scanning plane, the $\mathrm{Y}$-axis is perpendicular to the $\mathrm{X}$-axis in the transverse scanning plane, and the $\mathrm{Z}$-axis is perpendicular to the transverse scanning plane (Figure 3). The formula for calculating the coordinates of three-dimensional laser foot points can be obtained as follows:

$$
\begin{gathered}
L=\frac{1}{2} c \Delta t \\
\left\{\begin{array}{l}
x \\
y \\
z
\end{array}\right\}=\left\{\begin{array}{c}
L \cos \beta \cos \alpha \\
L \cos \beta \sin \alpha \\
L \sin \beta
\end{array}\right.
\end{gathered}
$$

In the formula, $C$ is the propagation speed of the laser in the atmosphere, $\Delta t$ is the round-trip propagation time of the laser at the distance to be measured, $\alpha$ is the observation value of the transverse scanning angle, and $\beta$ is the observation value of the longitudinal scanning angle.

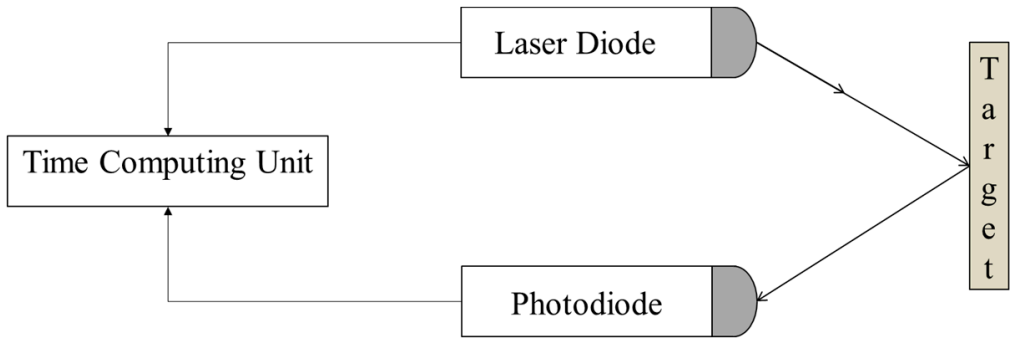

(a)

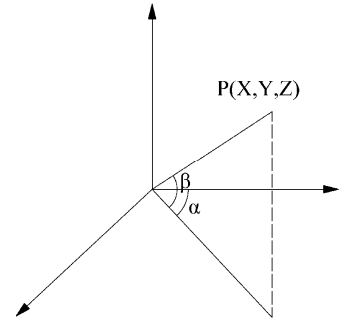

(b)

Figure 3. Schema of propagation time ranging method and internal coordinate system of laser detector. (a) schema of propagation time ranging method; (b) the internal coordinate system of laser detector.

The automatic laser scanning system of the empty area is mainly divided into horizontal scanning mode and vertical scanning mode.

- Horizontal scanning mode: The most commonly used scanning mode. First, the scanning head rotates vertically to the position of vertical angle $0^{\circ}$ (the upper part of the detector is straight) and begins the first round of complete $360^{\circ}$ horizontal scanning. After each circle of horizontal scanning, the scanning head increases the increment of steps set by the user along the vertical direction and starts the next circle of horizontal scanning until the vertical axis rotates $180^{\circ}$ in the vertical direction. During the last horizontal scan of the scanner head, the laser emission and receiving lens of the scanner head point in front of the detector (Figure 4).

- Vertical scanning mode: Vertical scanning is suitable for scanning under some special conditions. Especially, the scanning line obtained is perpendicular to the horizontal characteristics of the scanning object so that more details that are comprehensive can be captured. As shown in the figure, in the vertical scanning process, the scanning head first rotates from vertical angle position 0 (the vertical direction behind the detector) to vertical angle position $180^{\circ}$ (the laser-transmitting and -receiving lens of the scanning head points in front of the detector) along the vertical direction 
and completes the first vertical scanning. After each vertical scan, the scanning head increases a user-set increment along the horizontal direction and starts the next vertical scan until the horizontal axis rotates 360 degrees in the horizontal direction (Figure 5).

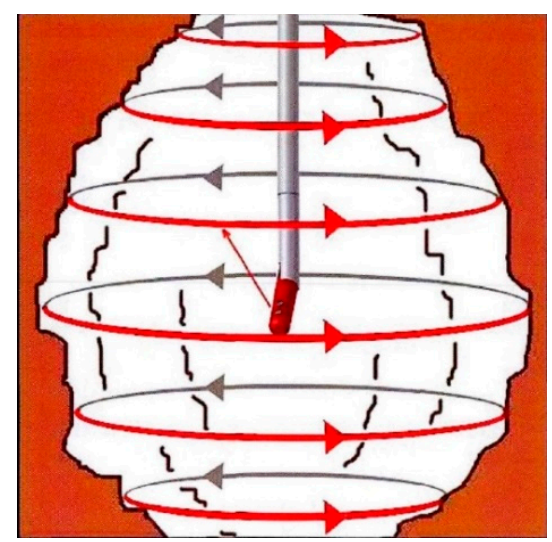

Figure 4. Horizontal scanning mode.

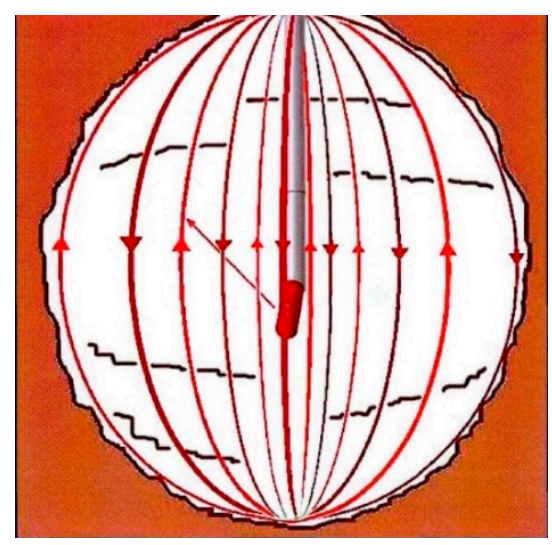

Figure 5. Vertical scanning mode.

\subsection{Data Processing of Laser Point Cloud}

After obtaining the original point cloud data via a laser three-dimensional measurement system, it is necessary to filter, stitch, and model the original point cloud data. Specifically, as follows:

Data filtering: Due to the influence of external environmental factors and the uneven reflection characteristics of the empty area wall during the scanning process, the final scanned point cloud data contain no distance points and bad points. At the same time, the rapid operation of a laser range finder during scanning will also lead to the phenomenon of an "intermediate medium point" in different phases of the laser beam, resulting in point displacement. For this reason, point cloud data are processed by filtering out single obvious bad points in scanning.

Firstly, according to the fixed space range of the working area, the point beyond this range can be considered as noise point filtering. Secondly, on the same scanning plane, if the distance between a point and its adjacent two points exceeds a certain trusted value, the point is considered distortion point filtering. However, considering the point of edge, because it is far from the scanning center, the distance between sampling points is very large. At this time, the angle between the combining point and the front and back points on the scanning line is considered as a distortion point if the angle between them is less than a certain confidence value (Figure 6). 


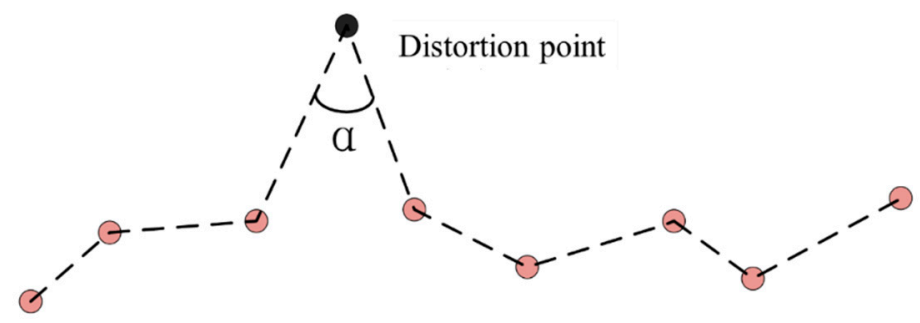

Figure 6. Distortion points on scanning line.

Data mosaic: Because the laser travels along a straight line, some areas will not be detected accurately if occlusion or obstruction occurs during the scanning process. Therefore, in order to detect the actual boundary of the airspace as accurately as possible, it is very important to select a reasonable detection location. For the complex shape of the empty area, we should try to carry out multi-point detection and then splice the point data obtained by multiple detection scans to form an area completely void of point cloud data. The essence of the data mosaic is to compute the rotation and translation transformation matrix $R, T$, which satisfies the following objective functions:

$$
f(R, T)=\min \sum\left[R \cdot p_{i}+T-q_{i}\right]^{2}
$$

where, $p_{i}$ and $q_{i}$ are point clouds that need to be aligned, and the upper formula is a highly nonlinear problem. The research of the data mosaic focuses on finding a fast and effective solution to this problem.

Because the point coordinates of the point cloud data obtained by each scan are relative to the coordinate system of the scan, the three-dimensional coordinates of the points obtained by different scanning times (different locations or angles of view) are in different coordinate systems. Therefore, we must try to put the three-dimensional point cloud data acquired by multiple scans into a common coordinate system, to obtain the complete three-dimensional point data in the empty space. This process is called a multi-point scanning data mosaic. The principle is shown in Figure 7.

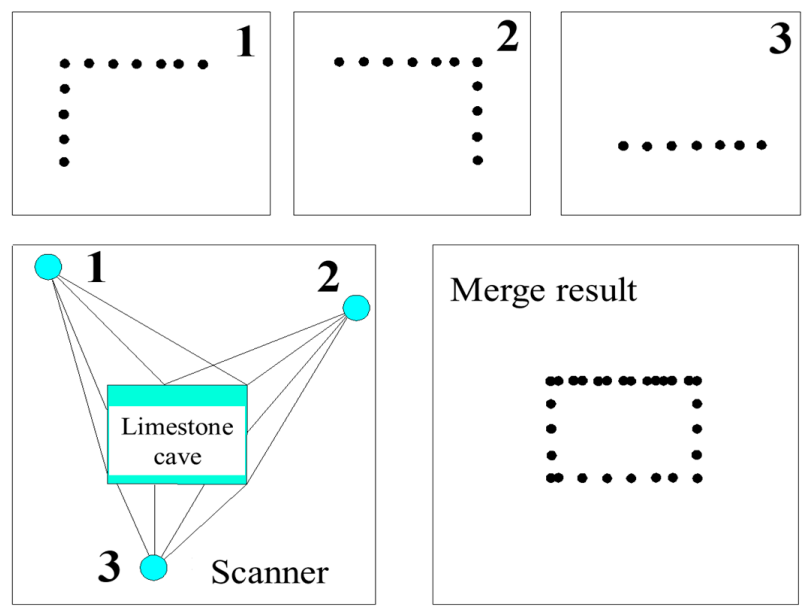

Figure 7. Mosaic of multi-point scanning data.

Specific cases are as follows: Boreholes \#1 and \#2 are selected to detect a karst cave twice, and the original point clouds detected by two boreholes are obtained through detection. The original point cloud data of borehole \#1 are filtered as shown in Figure 8a, and those of borehole \#2 are filtered as shown in Figure 8b. In each detection process, the borehole coordinates and initial azimuth angle are recorded. In the process below the probe, the system software automatically records the changes of depth, azimuth, and dip angle below and then splices the two detected data in the software to make the same detection point position coincide completely. The 3-D point cloud model of the karst cave formed by the splicing of boreholes \#1 and \#2 are shown in Figure $8 \mathrm{c}, \mathrm{d}$. The "point cloud creating 
entity" of "entity modeling" is used to automatically construct the three-dimensional figure contour of the cave and generate the three-dimensional entity model of the cave (Figure 8).

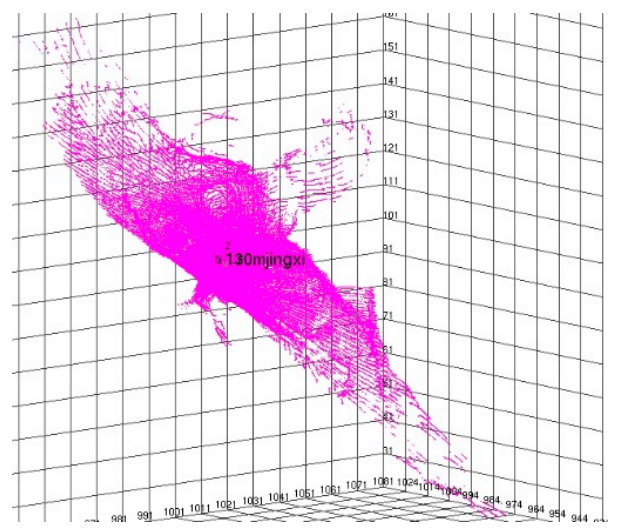

(a)

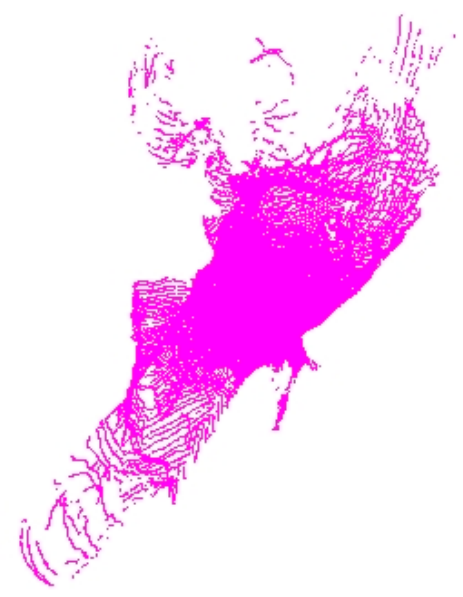

(c)

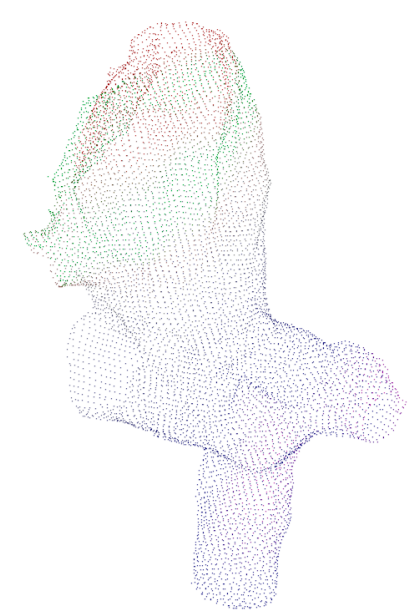

(e)

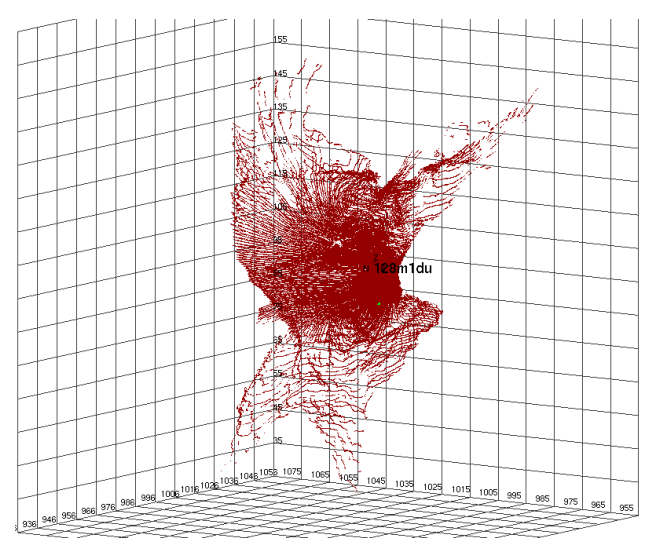

(b)

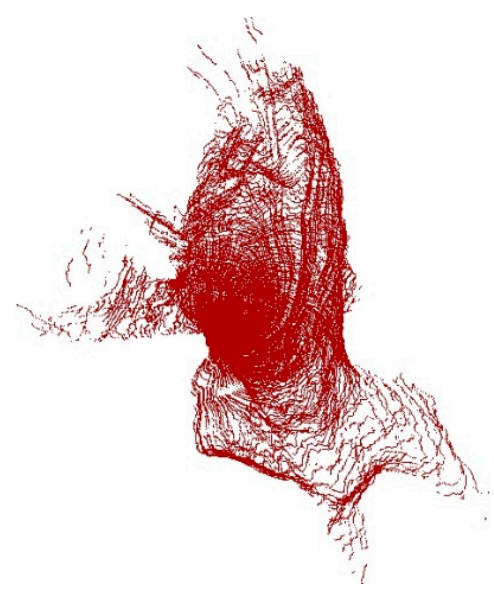

(d)

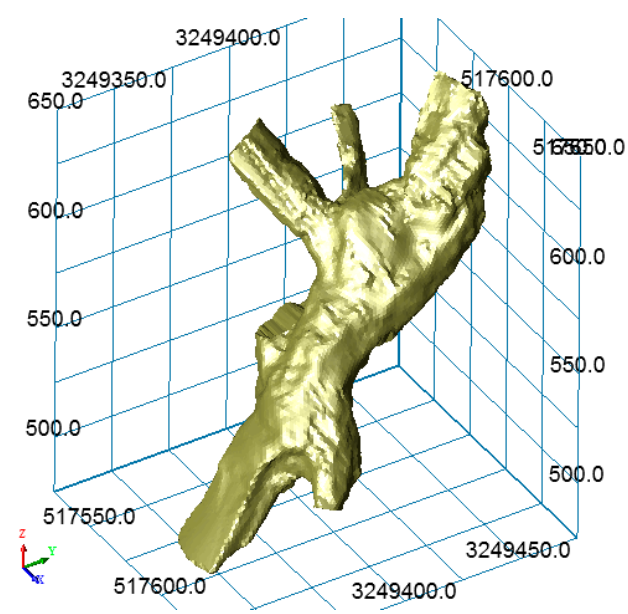

(f)

Figure 8. Construction of three-dimensional real model of karst cave. (a) Primitive point cloud of borehole \#1; (b) Primitive point cloud of borehole \#2; (c) Point cloud after splicing borehole \#1; (d) Point cloud after splicing borehole \#2; (e) Point cloud model after splicing boreholes \#1 and \#2; (f) Three-dimensional solid model of karst cave. 


\section{General Situation of Engineering Geology and Location and Quantitative Exploration Method of Jinan Metro's Karst Cave}

Traffic congestion in Jinan ranks first in the country all year round, and it is urgent to build the subway. Jinan Metro proposed the planning of the urban core area express line ( $\mathrm{R}$ line) and the central city general line (M line). The express line consists of three lines: R1, R2, and R3. The central city's general line includes 7 lines, the loop line and the M1 to M6 lines, forming a "loop + radiation" line network structure. In 2015, the R1 line of the first line of Jinan Metro officially started. Since then, three lines in total have been started.

Jinan is also famous for its spring water. The origin of the spring water is mainly due to the barrier of the northern impermeable magmatic rock in the process of the northward runoff of karst water, and then the groundwater flows out in the limestone sky window under the large pressure of the water head. Therefore, the construction of Jinan Metro needs to pass through a large number of limestone formations with strong karst development. In order to ensure the rapid and safe construction of the subway, it is very necessary to carry out meticulous exploration and treatment of karst caves in karst areas.

\subsection{General Situation of Engineering Geology}

The length of the Wangfu village station to the Dayang village station on the R1 line of Jinan Metro is about $2033 \mathrm{~m}$. This subway section passes through the middle weathered-limestone development area. The length of the left line tunnel through limestone is about $725 \mathrm{~m}$, and the length of the right line tunnel is about $798 \mathrm{~m}$. Preliminary investigation data show that the uniaxial compressive strength of moderately weathered limestone is $34.2-83.2 \mathrm{Mpa}$. The geological boreholes along the tunnel reveal karst caves in the middle weathered-limestone section. The main source of groundwater is limestone fracture karst water, which is the largest water area in the central and western parts of Jinan. The section is a rich water area, where the water supply is large, and the groundwater is confined (Figure 9).

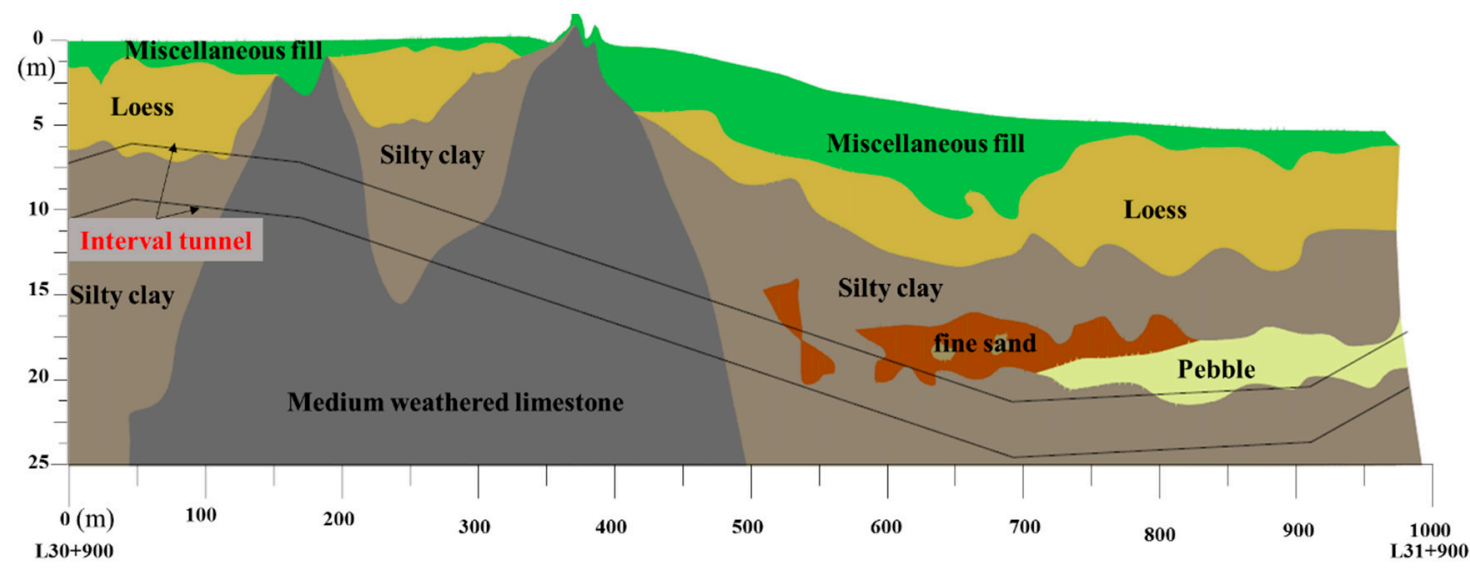

Figure 9. Geologic profile of the distance between the Wangfu village station and the Dayang village station.

The hydrogeological map shows that the interval through the weathered-limestone section is the largest water area in the central and western part of Jinan. The output of a single well of fractured karst water is more than $10,000 \mathrm{~m}^{3} / \mathrm{d}$, which indicates that this section is a water-rich area with large water recharge and confined groundwater (Figure 10). The figure below shows one of the exposed karst caves (Figure 11). 


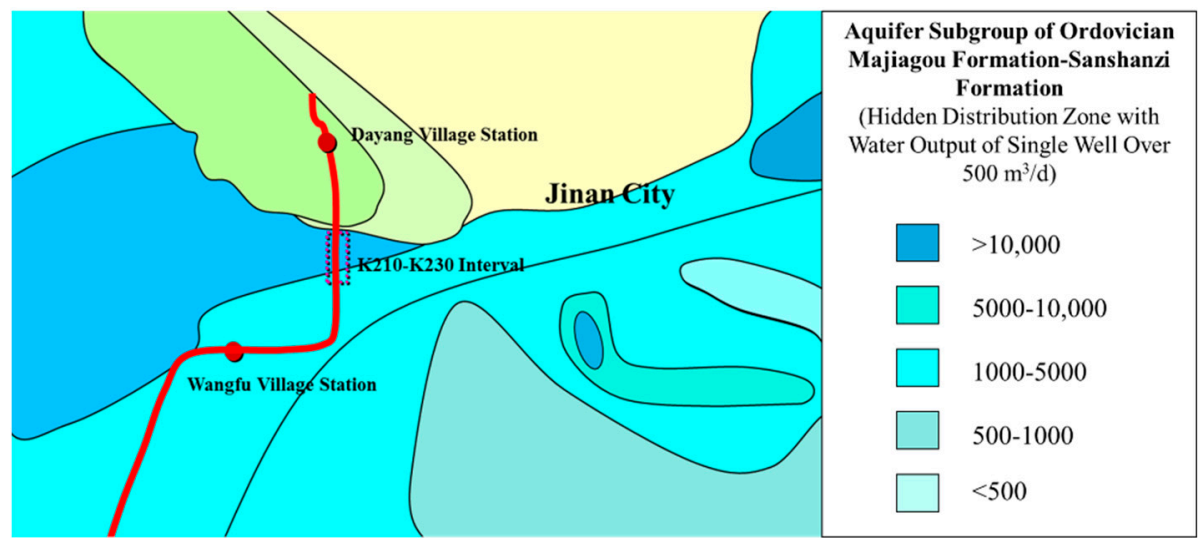

Figure 10. Geologic profile of the distance between the Wangfu village station and the Dayang village station.

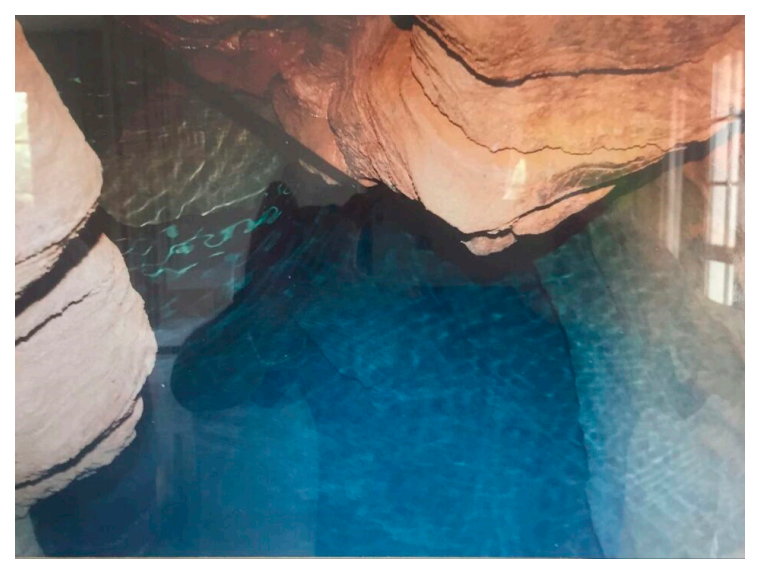

Figure 11. Exposed water-bearing karst cave.

\subsection{Location Exploration Method of Karst Cave}

Table 1 mainly introduces six common geophysical methods under different detection principles. Each of them has different characteristics.

In accordance with the characteristics of geophysical prospecting and the engineering geology of the R1 line, the most suitable geophysical method was selected. First, the subway was built in the urban area, where the surface soil is thicker. The seismic wave reflection method and the ground-penetrating radar method lead to more disturbances. Therefore, these two methods are not applicable. Second, because of the abundance of groundwater in the interval, the microgravity method is not applicable. Third, the upper part of the subway line is a highway, and the high-density electrical method leads to certain destructiveness on the road surface. Finally, the transient electromagnetic method is more suitable for the comparison between the land sonar method and the transient electromagnetic method. The principle of the transient electromagnetic method is that a pulsed magnetic field is transmitted to the front of the working face using an ungrounded line. When the current in the transmission line is abruptly disconnected, the two eddy fields will be excited to maintain the magnetic field (that is, one field) before the disconnected current, the size, and attenuation of the two eddy current field and the electricity of the surrounding medium. This is related to the electrical distribution of the surrounding medium. The variation of the secondary field with time is observed during the first field intermittence. After processing, the electric property, the scale, and the form of the underground medium can be understood to achieve the aim of detecting the target. 
Table 1. The characteristics of different geophysical methods.

\begin{tabular}{|c|c|}
\hline Prediction Method & Characteristic \\
\hline $\begin{array}{l}\text { The seismic wave reflection } \\
\text { method [20] }\end{array}$ & $\begin{array}{l}\text { The detection accuracy is higher in the range of } 20-200 \mathrm{~m} \text { and the } \\
\text { detection effect is better for karst caves. However, the adaptability to thick } \\
\text { overburden soil is poor, and energy attenuation is faster. }\end{array}$ \\
\hline The land sonar method [21] & $\begin{array}{l}\text { The prediction of medium and small caverns and fractured zones is } \\
\text { effective, but the velocity of each layer cannot be accurately obtained. }\end{array}$ \\
\hline $\begin{array}{l}\text { The high-density electrical } \\
\text { method [22] }\end{array}$ & $\begin{array}{l}\text { No filling cavern or water-rich cavern with the obvious electrical } \\
\text { difference with surrounding rock stratum is good. It can only be } \\
\text { qualitative but not quantitatively explored. }\end{array}$ \\
\hline $\begin{array}{l}\text { The transient electromagnetic } \\
\text { method }[23,24]\end{array}$ & $\begin{array}{c}\text { It is sensitive to large water-filled low-resistivity zones and has the ability } \\
\text { to penetrate low-resistance coverage. The depth of detection is large. } \\
\text { However, the resolution of empty caves or dry-filling karst caves is not } \\
\text { enough, so it is difficult to distinguish. }\end{array}$ \\
\hline $\begin{array}{l}\text { The ground-penetrating radar } \\
\text { method }[25,26]\end{array}$ & $\begin{array}{l}\text { In the high-resistivity area, the detection depth is } 20-30 \mathrm{~m} \text { and the } \\
\text { detection effect is good for karst caves and faults. However, it is easy to be } \\
\text { affected by the surface soil, and the detection depth is greatly reduced. }\end{array}$ \\
\hline The microgravity method [27] & $\begin{array}{l}\text { Under flat terrain, it is widely used in karst investigation. However, } \\
\text { factors such as topography fluctuation, sediment thickness, and } \\
\text { fluctuation of diving surface are relatively large. }\end{array}$ \\
\hline
\end{tabular}

The main reason for choosing high-density resistivity method and transient electromagnetic method for comprehensive detection is that the resistivity of underground rock is mainly influenced by mineral composition, water content, and temperature of rock. These complex factors result in the instability of rock resistivity and change in a large range. When there are fissures or fault zones in underground rocks and water-rich rocks with water-conducting channels, the resistivity of natural rocks located in these structural areas will be significantly reduced. There are obvious electrical differences with surrounding strata. Previous geological survey and site exposure show that it has the geological and physical basis of electrical detection. Each geophysical prospecting method has its own advantages and disadvantages. It is often difficult to satisfy the requirement of detection accuracy by using a single method. The combination of various geophysical methods can complement each other and verify each other.

We have made a total of 500 meters of detection, from L30+900-L31+450. Figure $12 b$ transient electromagnetic (TEM) locations are from L30+900-L31+40 and L31+110-L31+290, totaling $500 \mathrm{~m}$. Five sets of high-density resistivity have been made, each of which is $100 \mathrm{~m}$. Figure 12a shows the third group, which is from L31+150-L31+250. By means of resistivity anomaly, areas with strong karst development are detected. In these areas, we determined the locations of five boreholes, h1(110), h2 (230), h3 (280), h4 (315), and h5 (350) in Figure 12b, respectively. From the results of core drilling, it can be seen that all five boreholes encounter karst caves. 


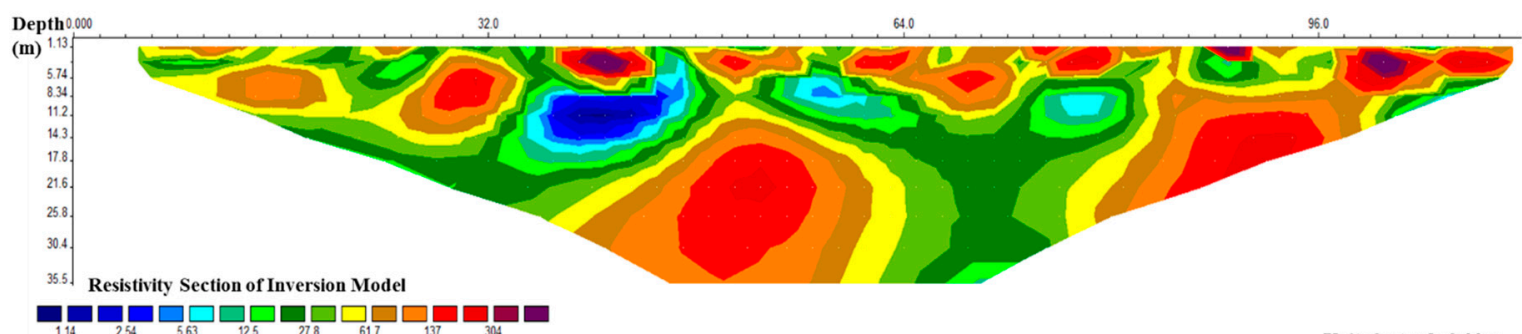

The unit of resistivity is $\Omega \cdot m$

Unit electrode $2.00 \mathrm{~m}$

(a)
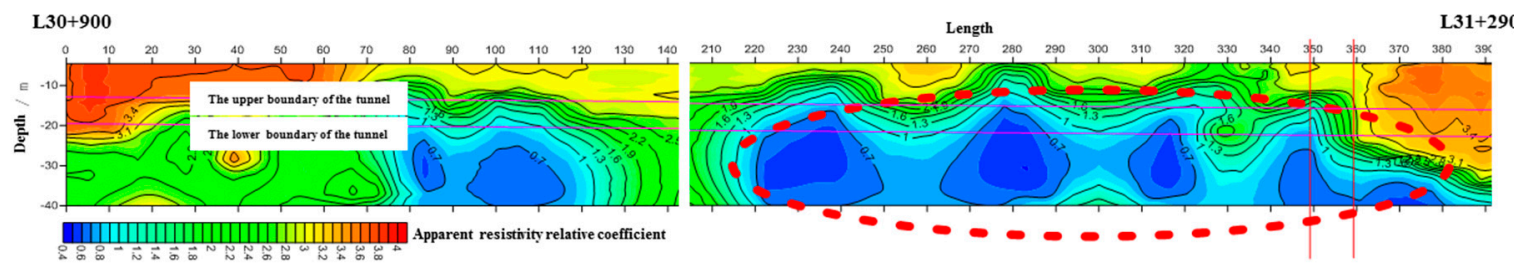

(b)

Figure 12. Comprehensive interpretation diagram of the high-density resistivity method and transient electromagnetic. (a) The result of high-density resistivity method; (b) The result of transient electromagnetic.

The core of each drill is shown in Figure 13.

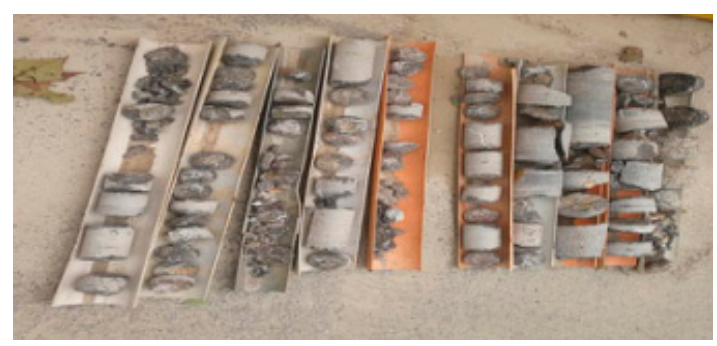

(a)

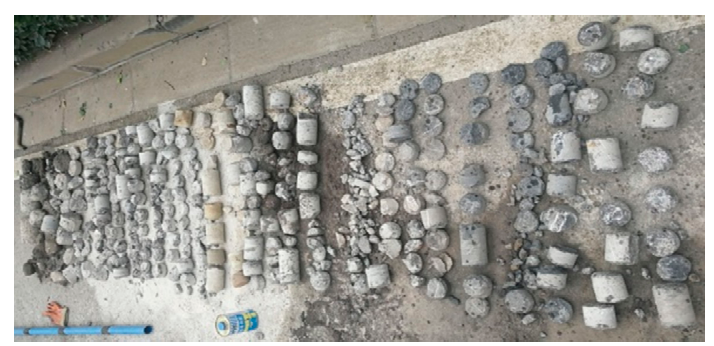

(c)

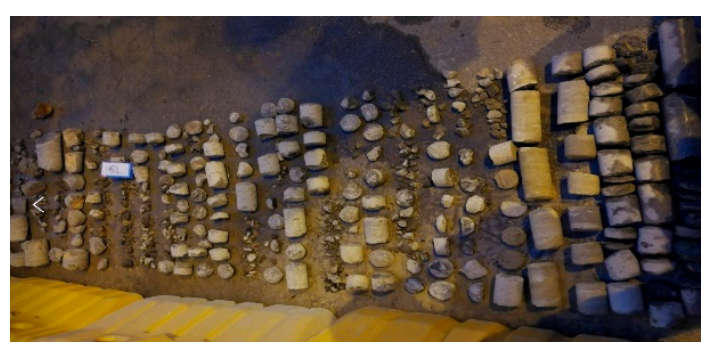

(b)

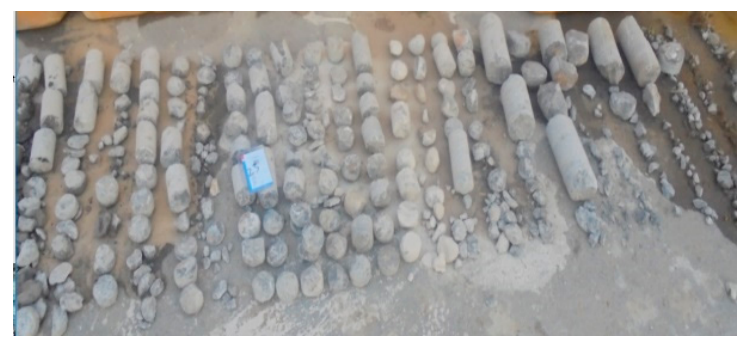

(d)

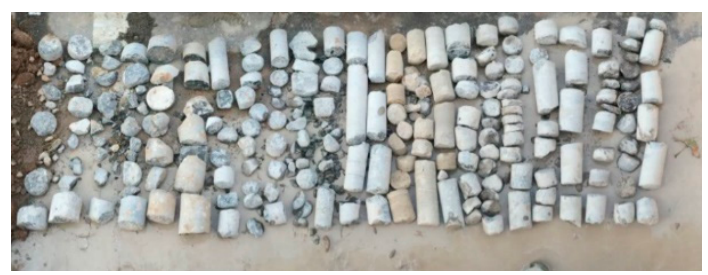

Figure 13. Drilling core drawing. (a) Coring of hole h1; (b) Coring of hole h2; (c) Coring of hole h3; (d) Coring of hole h4; (e) Coring of hole h5. 
Using five target drilling points, through the improvement of exploration equipment and exploration method, using panoramic probe sampling, combined with automatic ray compensation and automatic positioning technology, the acquisition of geological images in a borehole dark environment was achieved. Long distance accurate detection and real imaging of disaster sources such as karst cave were realized by 3D laser scanning (MDL, Edinburgh, Scotland).

The characteristics of 3D laser scanning (Figure 14) are as follows: (1) Rapidity: The spatial information of the karst cave can be obtained quickly, and the coordinate information of the karst cave surface can be measured in time. (2) Non-contact: We can scan the targets in a non-contact way. (3) Penetration: Under the water cut condition of the cave, it can cross the water body and reach the target surface. (4) Real-time, dynamic, and active: The target information is obtained by the reflection of light emitted by itself. It cannot be constrained by time and space, and the beam is quasi-parallel light, which avoids the inherent optical distortion error of conventional optical measurement. (5) High density and high precision: Laser scanning obtains target characteristics in a high-density and high-precision way. The laser point cloud is composed of point position coordinate data. Using a large lattice and a certain density grid to describe the entity information, the target information can be described more accurately.

Three-dimensional laser scanning devices are placed in five boreholes, as shown in Figure 15.

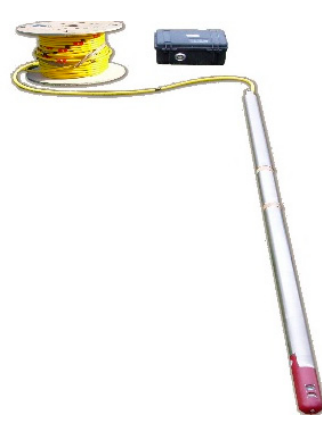

(a)

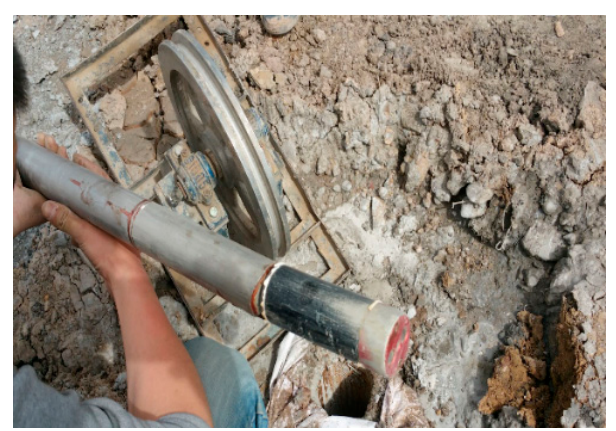

(b)

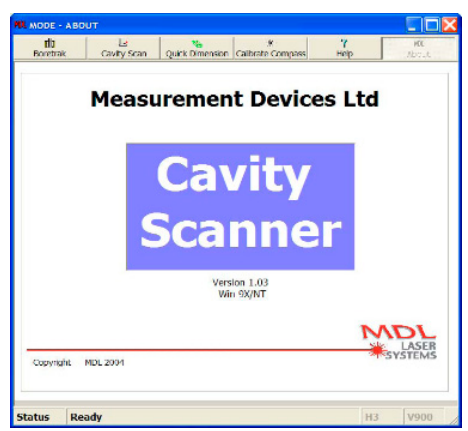

(c)

Figure 14. Laser scanning equipment and operation interface. (a,b) Laser scanning equipment; (c) operation interface.

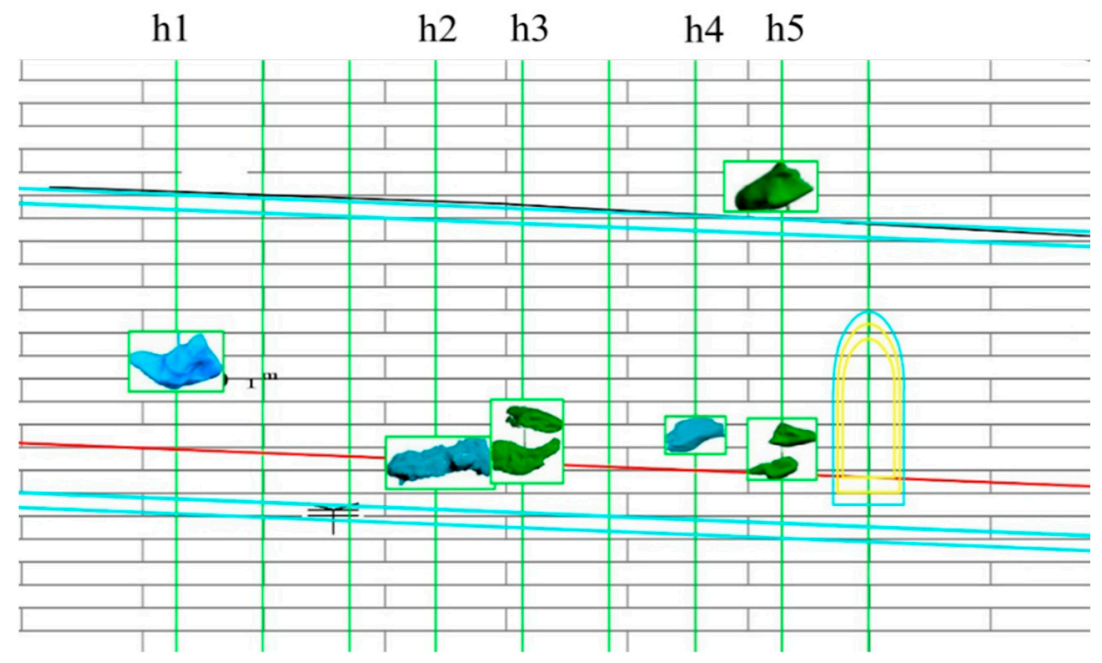

Figure 15. Karst cave distribution map.

\subsection{Three-Dimensional Model of Karst Cave}

h1 measured a cave about $1 \mathrm{~m}$ high at about $19.1 \mathrm{~m}$ underground, with a volume of about 2 cubic meters. The three-dimensional model of the cave is shown in Figure 16. 


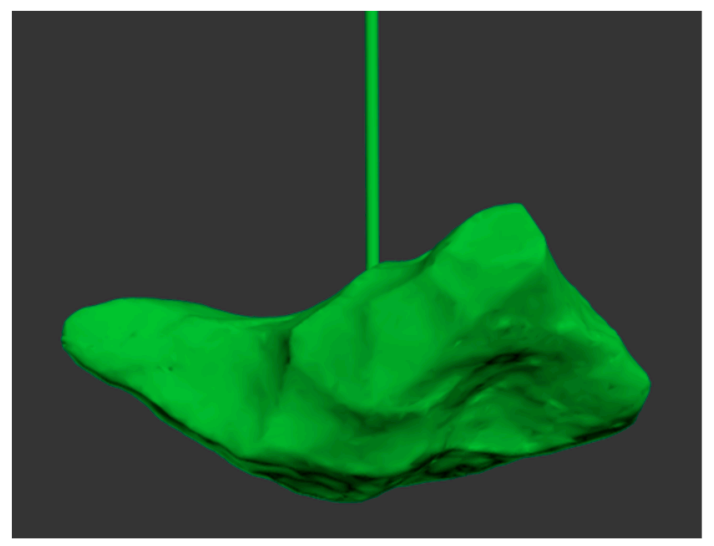

Figure 16. The three-dimensional model of the cave (h1).

$\mathrm{h} 2$ measured a cave about $1.5 \mathrm{~m}$ high at about $21 \mathrm{~m}$ underground, with a volume of about 3 cubic meters. The three-dimensional model of the cave is shown in Figure 17.

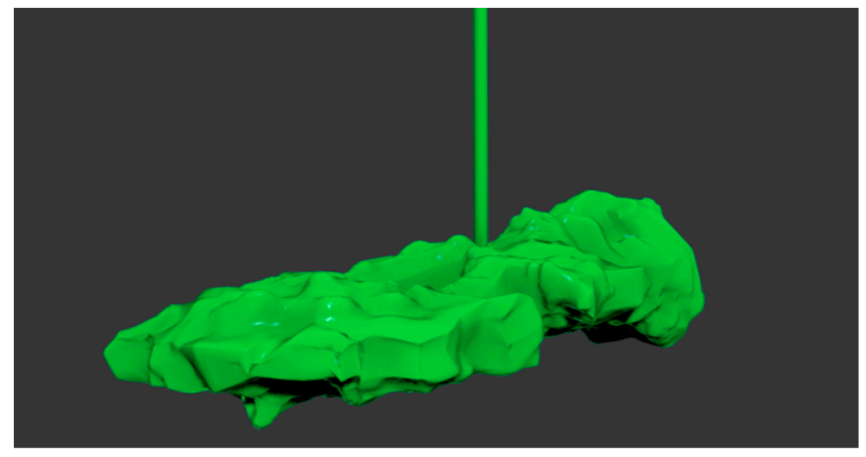

Figure 17. The three-dimensional model of the cave (h2).

h3 measured the beaded cave at about $19-22.5 \mathrm{~m}$ from the ground, with a volume of about 3.44 and 3.6 cubic meters, respectively. The three-dimensional model of the cave is shown in Figure 18.

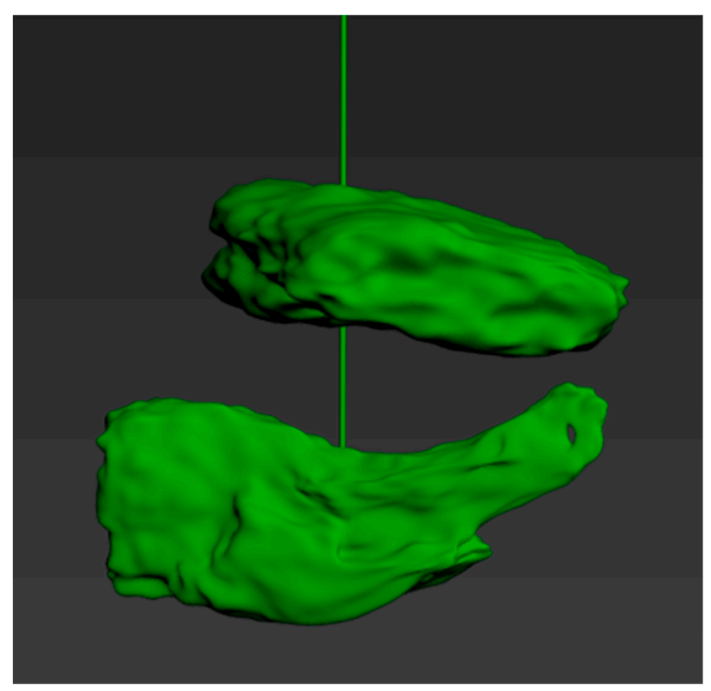

Figure 18. The three-dimensional model of the cave (h3).

h4 measured the cavern at about $2.8-20.5 \mathrm{~m}$ from the ground, with a volume of about 9 cubic meters. The three-dimensional model of the cave is shown in Figure 19. 


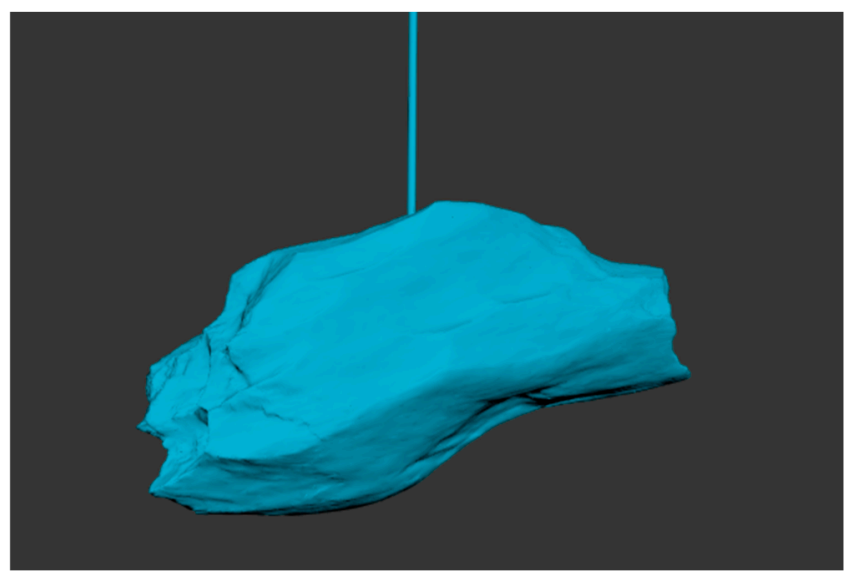

Figure 19. The three-dimensional model of the cave (h4).

h5 measured caves at about 16-21.5 m from the ground with a volume of about 2.1-2.7 cubic meters. The three-dimensional model of the cave is shown in Figure 20.

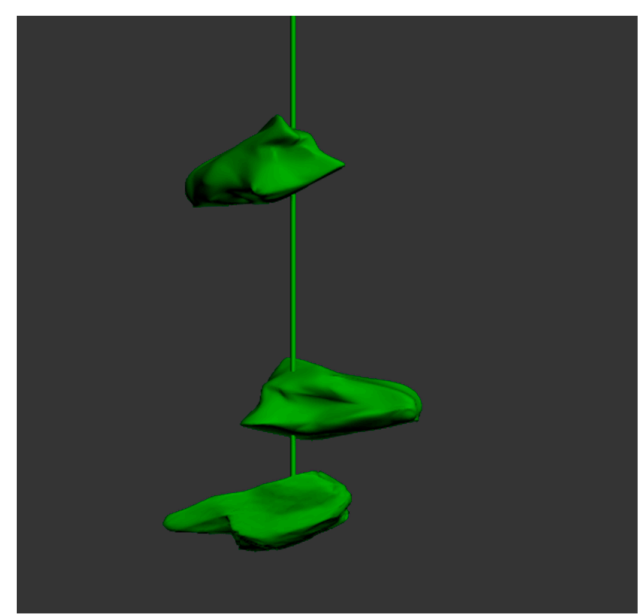

Figure 20. The three-dimensional model of the cave (h5).

The volume of each cave is shown in Table 2.

Table 2. The volume of each cave.

\begin{tabular}{ll}
\hline Drill Hole & Volume $\left(\mathrm{m}^{\mathbf{3}}\right)$ \\
\hline $\mathrm{h} 1$ & 3.02 \\
\hline $\mathrm{h} 3$ & 3.89 \\
\hline
\end{tabular}


Table 2. Cont.

\begin{tabular}{ll}
\hline Drill Hole & Volume $\left(\mathrm{m}^{3}\right)$ \\
\hline
\end{tabular}

At the same time, the high-definition camera function was mounted on the laser three-dimensional detection system. The results are shown in Figure 21.
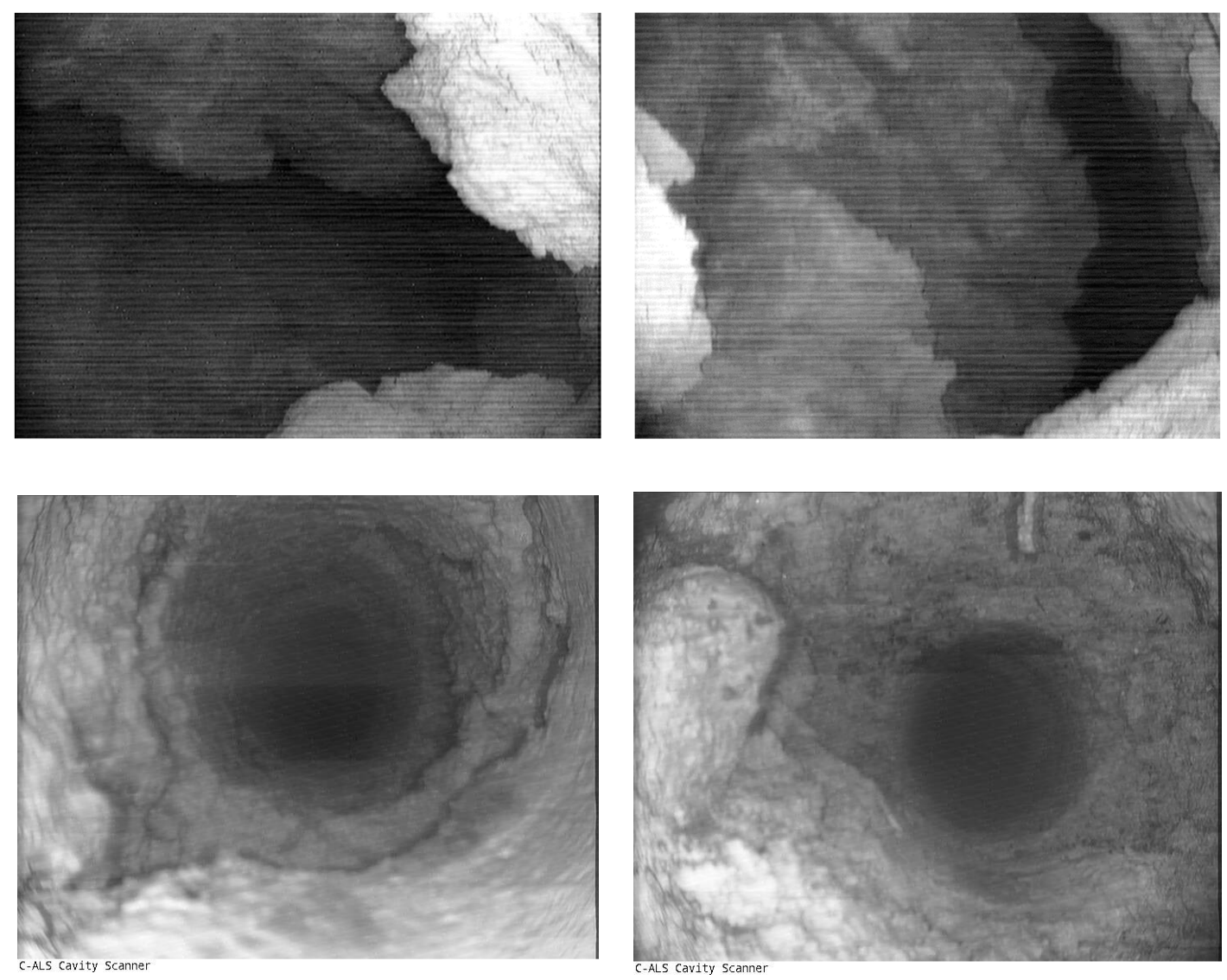

Figure 21. Intra-hole photography.

\section{Treatment of Karst Cave}

During the construction of metro, it is easy to cause the risk of ground subsidence. If there are karst caves above the subway, the risk of ground collapse increases sharply. Therefore, the above karst caves need to be harnessed. Sufficient safety distance should be ensured for karst caves under metro. If the safety distance from the floor is too small, it is easy to cause the settlement of the subway tunnel. 
According to the design experience, it is necessary to treat the floor karst cave within twice the diameter of the tunnel. For the karst caves on both sides of metro tunnel, the disturbance effect of shield excavation is mainly considered. According to engineering experience, when shield machine is excavated, the influence of karst caves beyond $5 \mathrm{~m}$ on both sides of the tunnel is small, only the karst caves within $5 \mathrm{~m}$ need to be treated. Reserve special holes for karst treatment in the segment structure for newly discovered karst caves during tunnel excavation and areas where settlement exceeds, or abnormality occurs in the later stages of the tunnel. Supplementary drilling is carried out in every 10 annular segments along the line, and the drilling depth is twice as far down as the tunnel bottom. According to the drilling results, grouting filling is carried out at the tunnel bottom to ensure the safety of operation.

If a karst cave is found, it can be treated. For a karst cave whose diameter is less than $1 \mathrm{~m}$, the volume is smaller and the cement slurry needed for filling is less. Pressure grouting with 1:1 cement slurry is directly applied to non-filled and semi-filled karst caves whose height is not more than $1 \mathrm{~m}$. For karst caves with a larger diameter, the volume required is larger. Sand blowing treatment can be carried out first, and then grouting reinforcement can be carried out. The small void of sand is conducive to cement deposition, reduces the diffusion of cement slurry in the range of ineffective diffusion, and effectively reduces the filling cost while guaranteeing the strength.

Through the limestone section, the uniaxial saturated compressive strength of limestone lies in the range of 34-83 MPa, the buried depth of the left tunnel is 14.7-25.4 m, and the buried depth of the right tunnel is $14.7-25.2 \mathrm{~m}$. The current maximum water level is $5.2 \mathrm{~m}$ below the ground, the anti-floating waterproof level is $1.9 \mathrm{~m}$ below the ground, and the maximum water head height at the bottom of the left and right tunnels is $23.5 \mathrm{~m}$ during the whole operation period. When the allowable opening of segment joint is $6 \mathrm{~mm}$, the elastic gasket can still resist water pressure of $0.8 \mathrm{MPa}$. Considering the high strength of rocks, the development of karst and fractured zones, the abundant karst water, the difficult control of tunneling posture during shield tunneling, and the difficulty in reaching the ideal state of segment assembling quality, in order to improve the waterproofing ability of shield segments, flexible seams with full rings are used in rock-piercing sections (Figure 22).

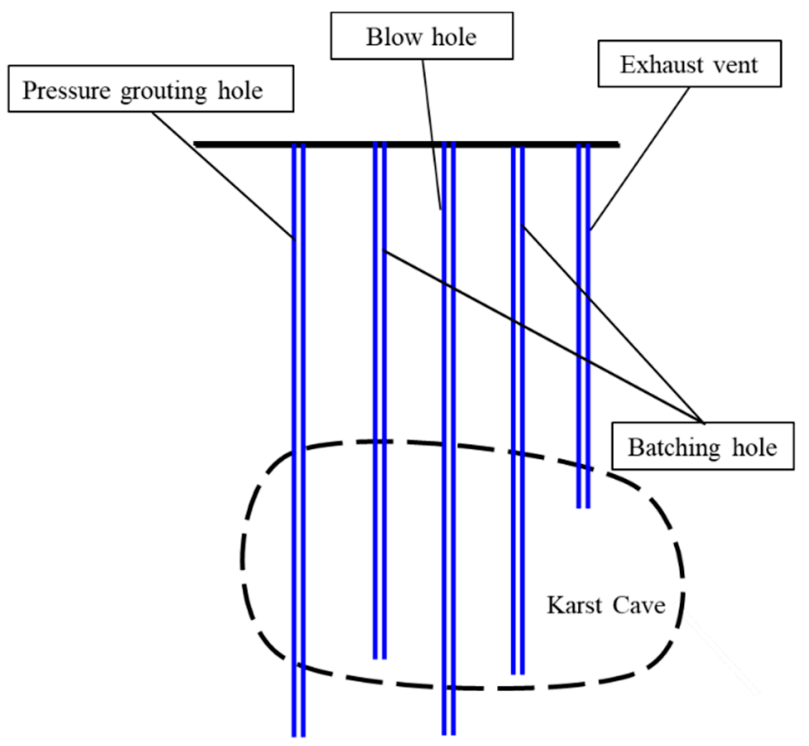

Figure 22. Drawing of grouting borehole.

\section{Conclusions}

1. The apparent resistivity of karst caves is higher than that of relatively intact strata. In a complex urban environment, high-density electrical method and transient electromagnetic method have high resolution for karst caves. Through the results of geophysical prospecting, targeted drilling can be carried out to avoid blind drilling. 
2. The laser point cloud is composed of point position coordinate data. Using a large lattice and a certain density grid to describe the entity information, the target information can be described more accurately. Making full use of the target drill hole and fine scanning of the cave via a 3-D automatic laser scanner, parameters such as the real shape and volume of the cave were obtained.

3. According to the construction experience and design principle, the treatment scope and method of karst caves in different locations are determined. The karst caves above the metro must be filled. The karst caves below the tunnel within twice the diameter need to be filled. The karst caves within $5 \mathrm{~m}$ on both sides of the tunnel need to be filled. When the diameter of karst cave is less than $1 \mathrm{~m}$, it can be filled with cement slurry directly. When the diameter of karst cave is larger than $1 \mathrm{~m}$, it needs to be filled with sand before grouting.

Author Contributions: Conceptualization, J.W. and L.L.; Methodology, S.S. (Shaoshuai Shi); Software, S.S. (Shangqu Sun); Validation, J.W., L.L. and S.S. (Shaoshuai Shi); Formal Analysis, J.W.; Investigation, S.S. (Shaoshuai Shi); Resources, J.W.; Data Curation, S.S. (Shangqu Sun); Writing-Original Draft Preparation, X.B.; Writing-Review \& Editing, Y.Z.; Visualization, X.B.; Supervision, L.L.; Project Administration, L.L.; Funding Acquisition, J.W.

Funding: The work is supported by National Natural Science Foundation of China (Grant No. 51809158, 51609129, 51809157), Shandong Provincial Natural Science Foundation, China (Grant No. ZR2018BEE045), China Postdoctoral Science Foundation (2018M630780).

Conflicts of Interest: The authors declare no conflict of interest.

\section{References}

1. Sun, S.; Li, L.; Wang, J.; Shi, S.; Song, S.; Fang, Z.; Ba, X.; Jin, H. Karst Development Mechanism and Characteristics Based on Comprehensive Exploration along Jinan Metro, China. Sustainability 2018, 10, 3383. [CrossRef]

2. Foley, A.E. The Use and Development of Some Groundwater Tracing Techniques for Wellhead Protection: Studies from the Corallian Limestone of Yorkshire. Ph.D. Thesis, University College London, 2006.

3. Hui, G.; Xu, J. A numerical simulation of impact of groundwater seepage on temperature distribution in karst collapse pillar. Arab. J. Geosci. 2017, 10, 10.

4. Li, S.; Liu, B.; Nie, L.; Liu, Z.; Tian, M.; Wang, S.; Su, M.; Guo, Q. Detecting and monitoring of water inrush in tunnels and coal mines using direct current resistivity method: A review. J. Rock Mech. Geotech. Eng. 2015, 7, 469-478. [CrossRef]

5. Zhong, S.; Wang, R. New Landsonar Method for Survey of Ground in Busy Town, Karst Caves in Mountain and Sea Bottom on Water. J. Eng. Geol. 2013, 21, 422-432.

6. Peng, C. The Combined Application of Seismic Imaging Method and High-Density Electric Method to the Survey of Karst CollapseAreas. Chin. J. Eng. Geophys. 2016, 13, 60-63.

7. Knapp, R.W.; Steeples, D.W. High-resolution common-depth-point reflection profiling: Field acquisition parameter design. Geophysics 1986, 51, 283-294. [CrossRef]

8. Carbonel, D.; Rodríguez, V.; Gutiérrez, F.; McCalpin, J.P.; Linares, R.; Roqué, C.; Zarroca, M.; Guerrero, J.; Sasowsky, I. Evaluation of trenching, ground penetrating radar (GPR) and electrical resistivity tomography (ERT) for sinkhole characterization. Earth Surf. Process. Landf. 2014, 39, 214-227. [CrossRef]

9. Ardestani, V.E. Detecting, delineating and modeling the connected solution cavities in a dam site via microgravity data. Acta Geod. Geophys. 2013, 48, 123-138. [CrossRef]

10. He, W.; Yu, R. Application of High-Density Resistivity Survey to Reconnaissance the Highway's Geological Disaster in the Mountainous Area. Geotech. Investig. Surv. 2009, 37, 89-94.

11. Xue, G.; Li, X.; Di, Q. The Progress of TEM in Theory and Application. Prog. Geophys. 2007, 22, 1195-1200.

12. Milsom, J.; Eriksen, A. Ground Penetrating Radar. In Groundwater Geophysics; Wiley: Chichester, UK, 1998.

13. Al-Fares, W.; Bakalowicz, M.; Guérin, R.; Dukhan, M. Analysis of the karst aquifer structure of the Lamalou area (Hérault, France) with ground penetrating radar. J. Appl. Geophys. 2004, 51, 97-106. [CrossRef]

14. Li, S.; Li, S.; Zhang, Q.; Xue, Y.; Ding, W.; Zhong, S.; He, F.; Lin, Y. Forecast of Karst-Fractured Groundwater and Defective Geological Condition. Chin. J. Rock Mech. Eng. 2007, 26, 217-225.

15. Jiang, W. Combination of Geophysical and Conventional Boring Methods for the Investigation of an Industrial Building over Abandoned Mining Areas in Zhangqiu. Soil Eng. Found. 2017, 3, 364-368. 
16. Waltham, D.T.; Bell, F.G.; Culshaw, M.G. Sinkholes and Subsidence; Springer: Berlin, Germany, 2005.

17. Yang, B.; Fang, L. Automated Extraction of 3-D Railway Tracks from Mobile Laser Scanning Point Clouds. IEEE J. Sel. Top. Appl. Earth Obs. Remote Sens. 2015, 7, 4750-4761. [CrossRef]

18. Gallay, M.; Hochmuth, Z.; Kaňuk, J.; Hofierka, J. Geomorphometric analysis of cave ceiling channels mapped with 3-D terrestrial laser scanning. Hydrol. Earth Syst. Sci. 2016, 20, 1827. [CrossRef]

19. Ordóñez, C.; Cabo, C.; Sanzablanedo, E. Automatic Detection and Classification of Pole-Like Objects for Urban Cartography Using Mobile Laser Scanning Data. Sensors 2017, 17, 1465. [CrossRef] [PubMed]

20. Liu, G.; Meng, X.; Ni, J.; Chen, Z.; Zhang, D. Evaluation of the two-dimension reflection seismic method towards the exploration of thrust-controlled mineral deposits in southwestern Fujian province, China. Geophysics 2018. [CrossRef]

21. Zhong, S. Land sonar method and effectiveness. Geophys. Geochem. Explor. 1997, 21, 172-179.

22. Guo, D.D.; Zhao, L.H.; Gao, Z.J. High-density electrical method used in the application of karst collapse. Ground Water 2011, 33, 108-110.

23. Christiansen, A.V.; Auken, E.; Sørensen, K. The transient electromagnetic method. In Groundwater Geophysics; Springer: Berlin/Heidelberg, Germany, 2006; pp. 179-226.

24. Li, X.; Xue, G.; Yin, C. Migration Imaging of the Transient Electromagnetic Method; Springer: Singapore, 2017.

25. Arifi, M.H.; Jamaluddin, T.A.; Husin, H.; Ismail, A.; Abbas, A.A.; Nordin, M.N.M.; Othman, N.A. Comparison of Geological Mapping with Electrical Resistivity and Ground Penetration Radar Methods for Rock Fractured System Study. Chiang Mai J. Sci. 2016, 43, 1346-1357.

26. Annan, A.P.; Diamanti, N.; Redman, J.D.; Jackson, S.R. Ground-penetrating radar for assessing winter roads. Geophysics 2016, 81, WA101-WA109. [CrossRef]

27. Orfanos, C.; Apostolopoulos, G. 2D-3D resistivity and microgravity measurements for the detection of an ancient tunnel in the Lavrion area, Greece. Near Surf. Geophys. 2011, 9, 449-457. [CrossRef]

(C) 2019 by the authors. Licensee MDPI, Basel, Switzerland. This article is an open access article distributed under the terms and conditions of the Creative Commons Attribution (CC BY) license (http://creativecommons.org/licenses/by/4.0/). 